\title{
Key Technology and Application Research of Cryogenic Insulation for LNG Plant Under Polar Climate
}

\author{
Peigang Xin, Yanfang Zhang, Jian Tang, Fengyan Yang, and Haijun Yang
}

\begin{abstract}
Cellular glass is applied as cryogenic insulation material in central process module of YAMAL LNG Plant. Characteristics of cellular glass such as hard, fragile and so on, bring much difficulty to prefabrication and installation and easily leave quality risk. Based on the actual cryogenic insulation design and installation for YAMAL LNG Plant, this paper analyzes and researches insulation procedures for special-shaped pieces such as tee, elbow, valves where insulation quality problem easily takes place, finally to realize innovation in design and ensure the construction quality. These procedures and installation methods mentioned in this paper are based on the polar climate environment. Meanwhile, the rigorous design and perfect application effect fully meet the requirements of the cryogenic technology so that normal operation of liquefied natural gas processing plant can be effectively guaranteed.
\end{abstract}

Index Terms - LNG, cryogenic insulation, cellular glass.

\section{INTRODUCTION}

The main composition of LNG (Liquefied Natural Gas) is methane, colorless, tasteless, non-toxic, and non-corrosive. To improve the efficiency of transportation, LNG plant can transform natural gas under normal pressure into liquefied natural gas under $-162^{\circ} \mathrm{C}$, with its volume to $1 / 625$ by cooling. In order to maintain cryogenic environment requirement of liquefied natural gas (LNG), it is very important to design and construct insulation.

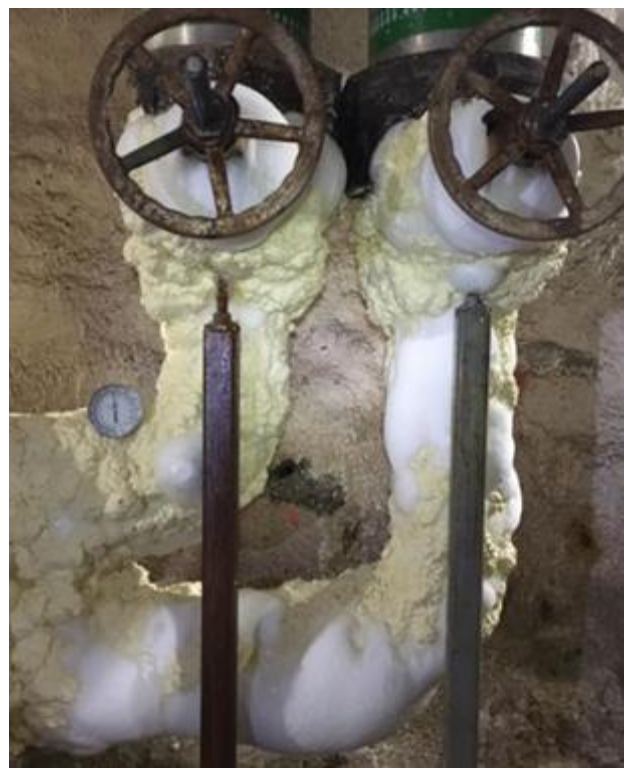

Fig. 1. Freezing of cryogenic insulation.

Manuscript received December 19, 2016; revised January 19, 2017.

Peigang Xin is with Design Department of Offshore oil engineering co., LTD, CO 266520 China (e-mail: xinpg@mail.cooec.com.cn).

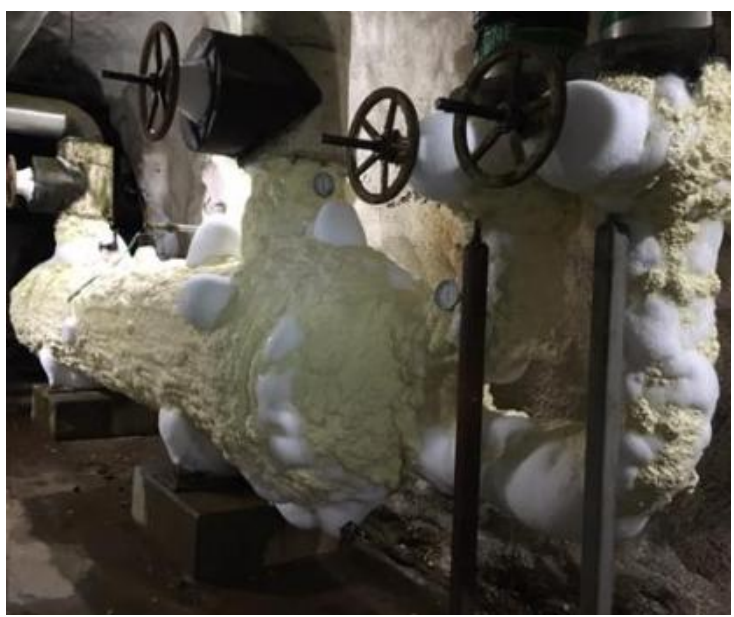

Fig. 2. Freezing of cryogenic insulation.

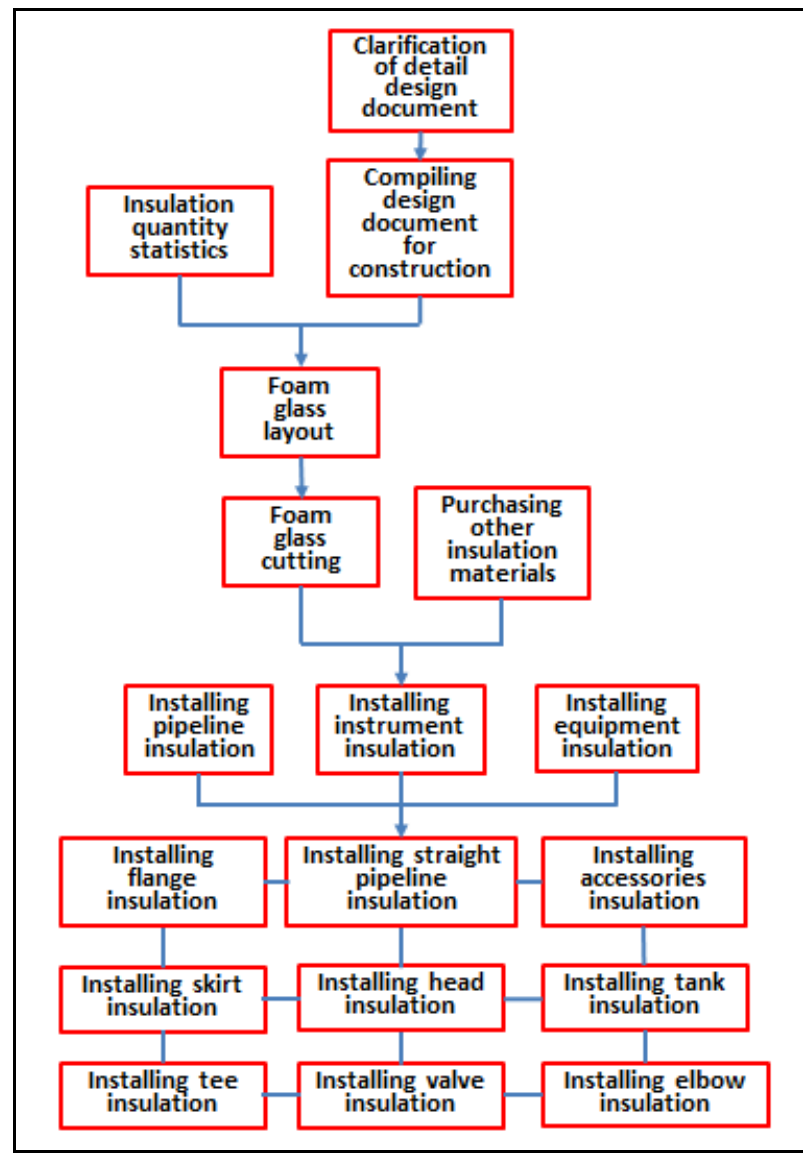

Fig. 3. Flow chart of cryogenic insulation construction.

Offshore oil engineering co., LTD. (COOEC) contract central processing module construction of YAMAL LNG Plant located in Yamal Nenets autonomous district to the east 
of the Yamal Peninsula, north of the Sabetta village of Russia. YAMAL LNG Plant project is located in the Arctic Circle, which belongs to the typical polar climate. Cellular glass is selected as cryogenic insulation material, whose shape of the factory is cuboid. Cellular glass' characteristics such as hard and fragile bring many difficulties to its prefabrication and installation. Especially for cryogenic insulation of special-shaped pieces such as tee, elbow, valves, it is very difficult and complex to prefabricate and install foam glass whilst it is easy to leave potential quality risk. Once insulation fail, seriously freezing will occur (see Fig. $1 \& 2$ ). From the perspective of design and installation, this paper analyzes cryogenic insulation in order to realize the innovation design and ensure the construction quality.

Please refer to Fig. 3 for flow chart of cryogenic insulation construction [1], [2]. The scope of compiling design document for construction includes typical insulation drawing for construction, insulation procedure for construction, insulation MS for construction, MS for prefabricating foam glass [3], submitting MAR for approval. The scope of cellular glass layout includes confirming specification of pipe section, confirming specification of segment, confirming prefabrication form of special-shape pieces, confirming layer of foam glass, confirming material utilization, confirming material utilization.

II. DESIGN AND INSTALLATION OF CRYOGENIC INSULATION FOR TEE [4]

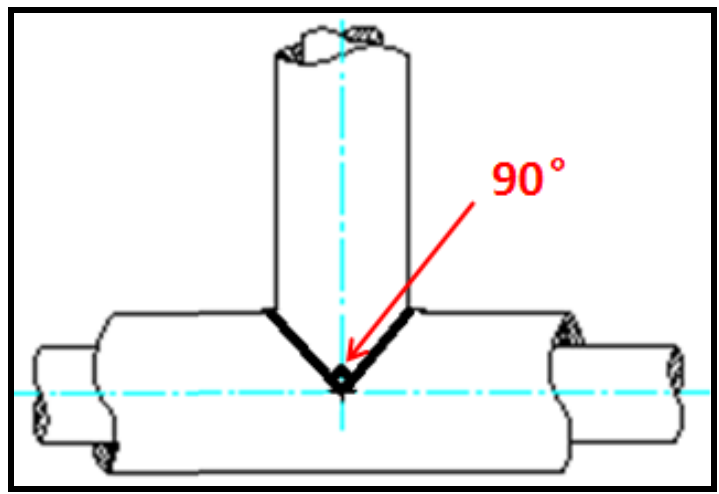

Fig. 4. Design of tee insulation.

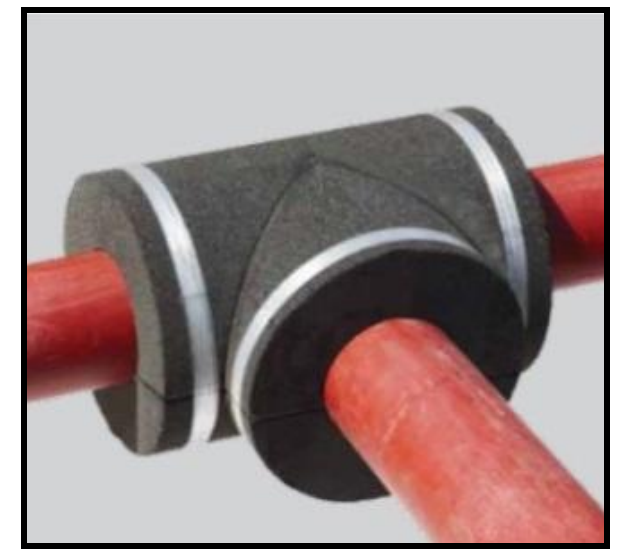

Fig. 5. Installation of tee insulation.

Whether equal tee or reducing tee, their intersecting lines are "saddle shape". Rigid insulation materials (Cellular glass) cannot be prefabricated just the same as saddle shape because of irregular shape, however only to be approximately cut, ensuring impervious seam and cold insulation effect ${ }^{[10]}$ (see Fig. 4\& 5).

1) For equal tee, cellular glass is prefabricated by the way of vertical cutting machine or two-dimensional semi-auto cutting machine for accurate cutting $45^{\circ}$ oblique and then be butted seamlessly. Cellular glass for equal tee insulation is also prefabricated along intersecting line.

2) For cellular glass prefabrication of reducing tee, intersecting line can be drew taking advantage of CAD, and then put drawings into two-dimensional semi-auto cutting machine for cutting.

\section{DESIGN AND INSTALLATION OF CRYOGENIC INSULATION FOR ELBOW}

It is very difficult to prefabricate and install cellular glass for elbow because of both being rigid and elbow's irregular surface. To ensure no gap between cellular glass and elbow for excellent insulation performance, different design of cellular glass shall be accomplished according to different size of elbow (see Fig. 6, 7).

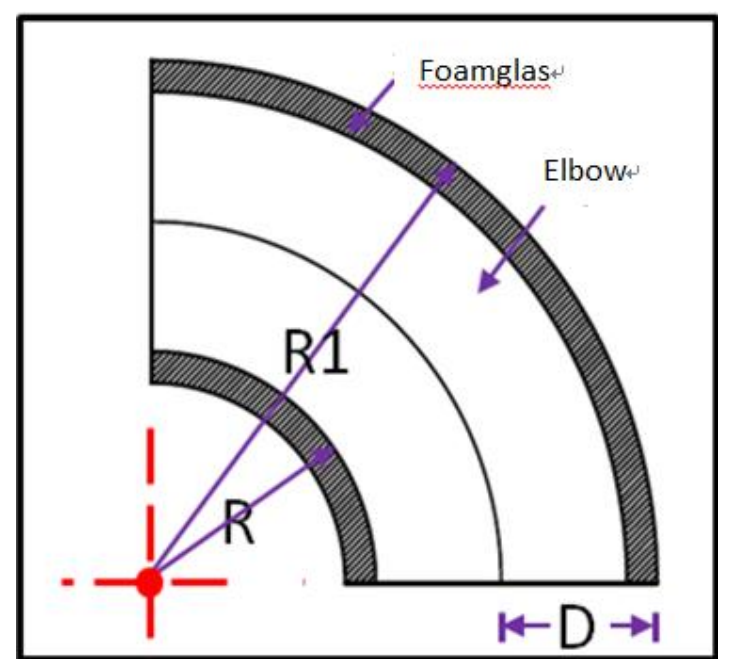

Fig. 6. Prefabricating principle for once shaping elbow.

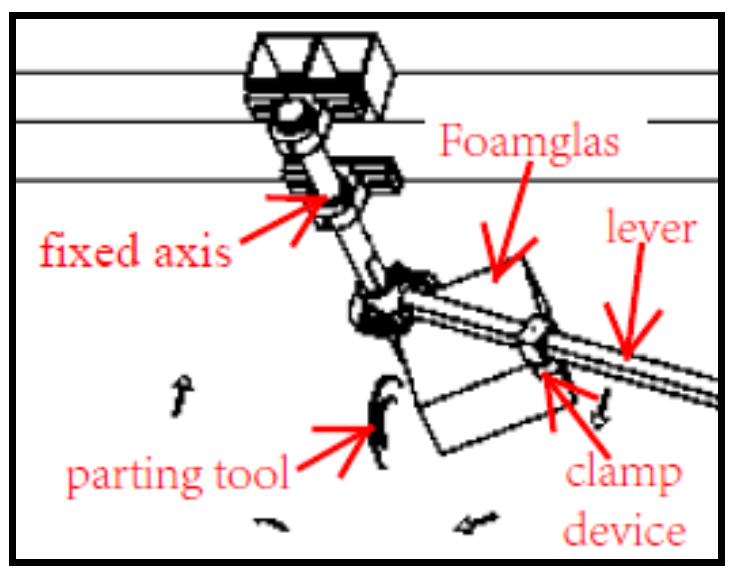

Fig. 7. Prefabricating principle for once shaping elbow.

1) Once shaping elbow should be adopted when elbow insulation outside diameter is 6" or less and insulation thickness is small. Prefabricating principle is shown in Fig. 
6. Firstly, corresponding cellular glass cuboid shall be prefabricated with length, width, height being respectively $\mathrm{R} 1, \mathrm{R} 1, \mathrm{D}$ and then to diagonally fix cellular glass cuboid by clamp device and push the lever around to prefabricate cellular glass [5]. It is important to note that the above cellular glass prefabrication for elbow could not be carried out because fixed axis will be located inside foam glass cuboid when the thickness of insulation is larger than 6" which is equal or greater than the R. When cellular glass shall be installed with multi-layers structure, only the first layer can be cut by once shaping elbow in order to meet the requirements of staggered joints between sequential layers [6].

2) When insulation outer diameter is 6" or less and insulation thickness is a little bigger, cellular glass shall be prefabricated as square or three-way for elbow insulation. For square elbow, no external force in the vertical direction of the joint can lead to loose joint. Therefore, artificially external force shall be imposed and removed after adhesive already cure when two butt joints are fixed. If above requirements can't be met, three-way elbow shall be chose.

For three-way elbow, larger space will be occupied because of its inherent structural characteristics. If space is not enough for installing, three-way elbow should not be chose.

No gap between outer face of elbow and inner surface of cellular glass could be left for above two elbow forms. Loose wool or other flexible material should be filled inside gap in order to satisfy the demands of heat preservation [7]. In addition, an additional insulation thickness should be added when insulation requirement is strict because the inner side of elbow is not a right angle which can lead to local thinned insulation thickness (see Fig. 8).

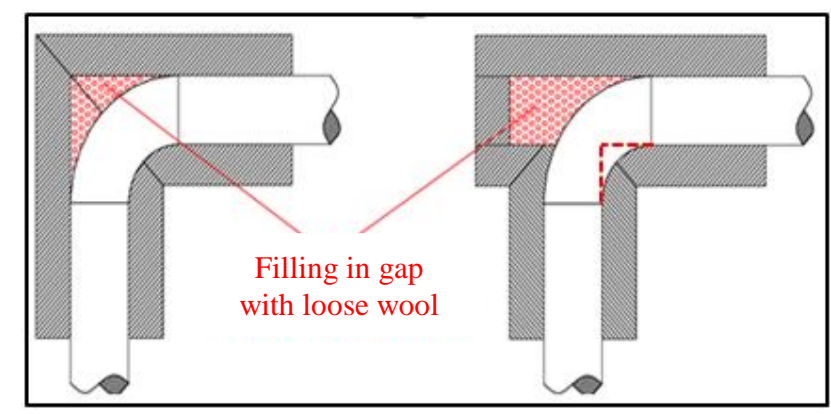

Fig. 8. Square or three-way elbow.

3) Cellular glass shall be prefabricated as mitre type for elbow insulation when elbow insulation outer diameter is greater than 6". Cellular glass shall be firstly cut as shell with circumferential direction angle 180 degree. And then shell is cut into a certain number of curvature pieces according to the design size, finally to assemble these pieces into an integrated mitre elbow.

The number and size of prefabricated pieces shall be accomplished by the way of CAD lofting (see Fig. 9.). The width of both ends for each piece of cellular glass is different. The narrower end should be more than width of stainless steel band selected during constructing insulation on site. Another end width should be less than $100 \mathrm{~mm}$, otherwise inner side of mitre elbow won't be able to close to outer surface of elbow.
When cellular glass is divided into two layers or more, staggered joint can be achieved through extending width of cellular glass pieces located in two outmost side to avoid throughout joint [8].

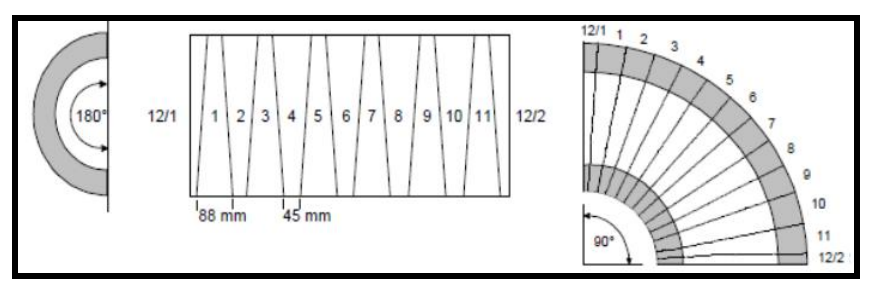

Fig. 9. Lofting for mitre type elbow.

\section{TYPICAL DESIGN AND CONSTRUCTION FOR VALVE} CRYOGENIC INSULATION

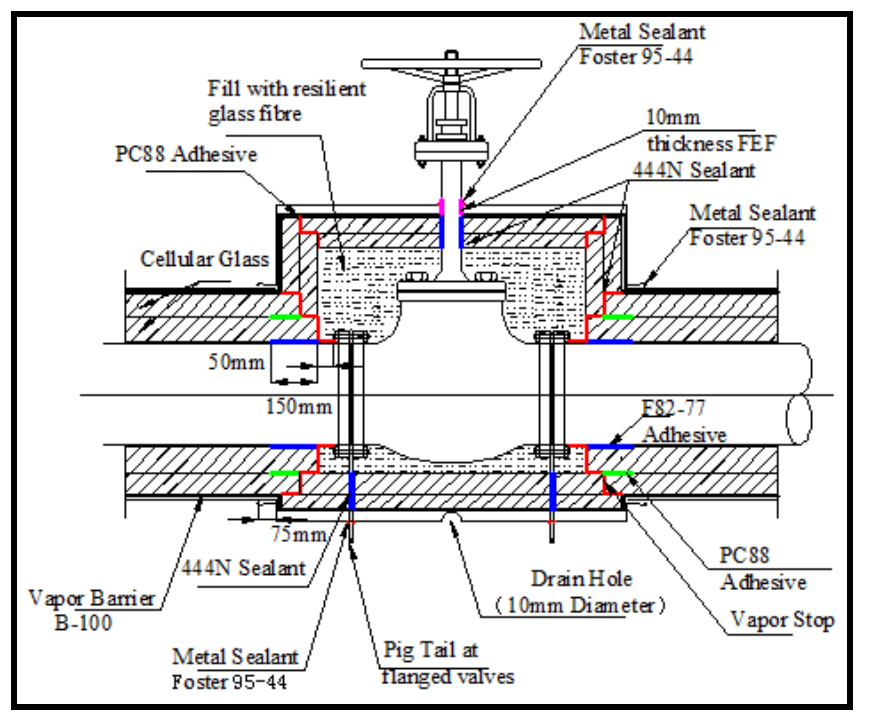

Fig. 10. Designing insulation for ordinary flange valve.

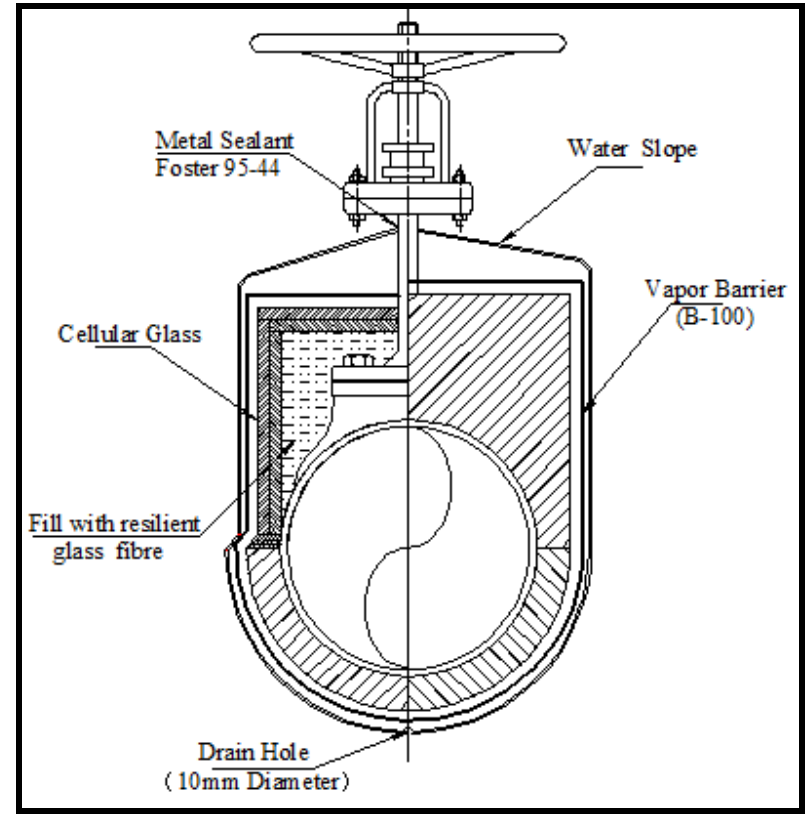

Fig. 11. Designing insulation for ordinary flange valve.

Because valve surface shape is complex and normal maintenance is required, cryogenic insulation for valve need be made as removable form. Especially for flange valve with potentially dangerous leak, requirement of detecting leakage should also be considered when designing insulation. 
1) Design features and materials application of ordinary insulation for valve (see Fig. 10\&11) [11]

(1) Insulation equal to insulation thickness shall be overlapped between cellular glass used for valve and adjacent straight pipe insulation. Vapor stop shall be firstly coated on two end surface to be overlapped, and after curing sealant $(444 \mathrm{~N})$ shall be coated to bond and fix cellular glass for preventing moisture from entering through joint. Because of 444N's soft characteristic after curing as sealing, it is easy to be opened at joint without destroying cellular glass so that insulation box for valve is removable.

(2) A bolt $+30 \mathrm{~mm}$ in length shall be kept between the end of straight pipe insulation and outer surface of flange to ensure that bolt can be successfully removed. F82-77 shall be applied between the inner surface of cellular glass for pipe insulation and outer surface of pipe to prevent thermal expansion.

(3) Drain hole with $10 \mathrm{~mm}$ in diameter shall be designed at the low end of jacketing to effectively eliminate the condensed water.

(3) Pig tail shall be installed at gaps located in companion flange and flange for connecting valve. $100 \mathrm{~mm}$ or so shall be kept through external surface of jacketing to detect leakage. $444 \mathrm{~N}$ shall be applied between cellular glass for valve insulation and valve stem and metal sealant shall be applied between jacketing and valve stem to both be removable and waterproof. Resilient wool shall be filled inside insulation box.

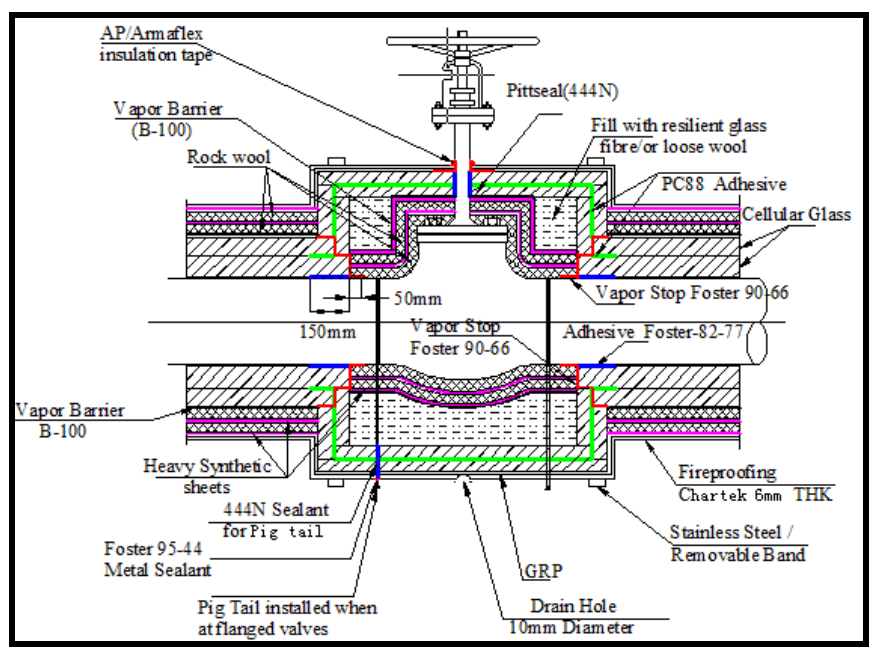

Fig. 12. Design features and materials application of compound insulation for valve.

2) Design features and materials application of compound insulation for valve (see Fig. 12\&13)

(1) The design is compound insulation for valve with cryogenic insulation, acoustic insulation and proofing fire. The following materials are selected such as cellular glass, rock wool \& heavy synthetic sheet, painting respectively for the above three requirement. Insulation overlapping, vapor stop and sealant $(444 \mathrm{~N})$ are applied like ordinary insulation for valve. Thus, it is also easy to be opened at joint without destroying cellular glass so that insulation box for valve is removable. GRP (glass reinforced polyester) shall be applied as jacketing to replace stainless steel so that painting is easily coated because of outer rough surface of GRP.

(2) Bolt $+30 \mathrm{~mm}$ in length shall be kept between the end of straight pipe insulation and outer surface of flange to ensure that bolt can be successfully removed. F82-77 shall be applied between the inner surface of cellular glass for pipe insulation and outer surface of pipe to prevent thermal expansion.

(3) Drain hole with $10 \mathrm{~mm}$ in diameter shall be designed at the low end of jacketing to effectively eliminate the condensed water.

(4) Pig tail shall be installed at gaps located in companion flange and flange for connecting valve. $100 \mathrm{~mm}$ or so shall be kept through external surface of jacketing to detect leakage. 444N shall be applied between cellular glass for valve insulation and valve stem and metal sealant shall be applied between jacketing and valve stem to both be removable and waterproof. Resilient wool shall be filled inside insulation box

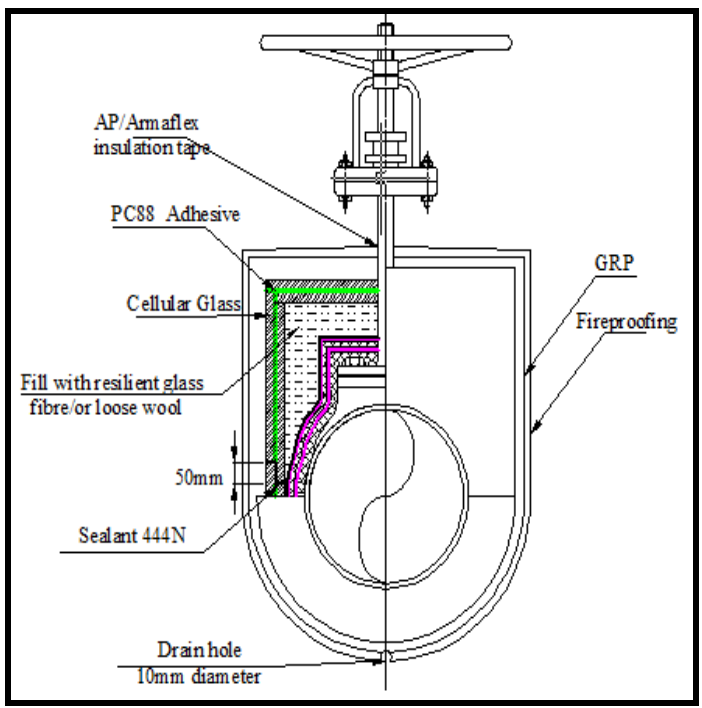

Fig. 13. Design features and material application of compound insulation for valve.

\section{CONCLUSION}

It was very important for cryogenic insulation to ensure normal operation of liquefied natural gas processing plant. Especially for Special-shaped pieces such as tee, elbow and valves, cryogenic insulation should be carried out by innovative design and careful installation. Otherwise, it was easy to leave hidden dangers. The above procedure and installation methods mentioned in this paper were based on the polar climate environment. Meanwhile, rigorous design and perfect application effect fully met the requirements of the cryogenic technology so that normal operation of liquefied natural gas processing plant could be effectively guaranteed.

\section{REFERENCES}

[1] H. J. Yang, "Construction technology research of cryogenic insulation for big lng core pipe," The third China Oil \& Gas Storage Technology Exchange Conference, Chengdu, China, May, 2012. 
[2] X. L. Wang, "Cryogenic insulation technology research for LNG pipe," in Proc. the third China Oil \& Gas Storage Technology Exchange Conference, Chengdu, China, May, 2012

[3] Standard Specification for Fabrication of Cellular Glass Pipe and Tubing Installation, ASTM C1639.

[4] Prefabrication and Field Fabrication of Thermal Insulating Fitting Covers, ASTM C450.

[5] Piping and Equipment Insulation, Norsok R-004

[6] Equipment and pipes heat insulation, SNIP SP 61.13330.2012.

[7] Standard Practice for Inner and Outer Diameters of Rigid Thermal Insulation for Nominal Sizes of Pipe and Tubing, ASTM C585.

[8] Standard Specification for Asphalt Used in Roofing, ASTM D312.

[9] Standard Test Method for Dimensions and Density of Preformed Block and Board-Type Thermal Insulation, ASTM C303.

[10] Standard Specification for Cellular Glass Thermal Insulation, ASTM C552.

[11] Handbook Insulation for Industries 2011, Committee Insulation Netherlands Industry (CINI).

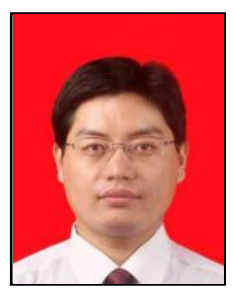

Peigang Xin was born in Shandong province of China on 1978, graduated in 2010 from Petroleum University of China with the master degree in oil \& gas storage and transportation engineering. Mr Xin is engaged in cryogenic insulation research for LNG pipeline in China Offshore Oil Engineer Corporation(COOEC).

He have already achieved much experience of cryogenic insulation in design, construction, material and so on. He ever took part in many international LNG projects as insulation engineer such as gorgon lng project, ichthys lng project and leader insulation engineer for yamal lng project. By now, he has presided over the editing of Series of technical documents including insulation design, construction and material application. For long time, he always focus on application and construction craft insulation material which is normally used in LNG project such as cellular glass, flex elastomeric foam (FEF) and Polyisocyanurate Foam (PIR). At the same time, he took most responsibilities of research project about cryogenic insulation funded by government of China.

Peigang Xin was ever awarded best employee of COOEC for his excellent achievement in cryogenic insulation. At the same time, engineer team led by Mr Xin was rated twice best group of COOEC. 